\title{
PRIMARIES THROUGH THE LOOKING GLASS: THE ELECTORAL EFFECTS OF OPENING THE SELECTION OF TOP CANDIDATES*
}

\author{
Javier Astudillo \& Ignacio Lago \\ Universitat Pompeu Fabra \\ Department of Political and Social Sciences \\ Ramon Trias Fargas 25-27 \\ 08005 Barcelona, Spain \\ javier.astudillo@,upf.edu \\ ignacio.lago@upf.edu
}

DRAFT VERSION: SEPTEMBER 2019

\begin{abstract}
In this paper the foundations of existing research regarding the effects of plebiscitarian selection mechanisms on candidates' electoral strength are revisited. While for existing research parties' decision-making is not nested, we argue that party primary effects entail the interdependence of party procedures for candidate selection. This paper assesses the validity of the two approaches. Using original data from 7 parties and 296 regional elections in Canada, Germany and Spain, and from 62 preelection polls in Germany and Spain, we show that, other things equal, primary-selected candidates are not stronger than those selected by other procedures. However, there is evidence of a penalty for those parties not selecting candidates by primary when their main rival does, in particular when the primary election is not divisive and is held closer to the general election.
\end{abstract}

Key words: Political Party, Leader, Election, Primaries.

*We acknowledge support from the Spanish Minister of Science, Innovation and Universities (Grant number AEI/FEDER CSO2017-85024-C2-1-P), the Catalan Institut for Self-government Studies (IEA), and the ICREA under the ICREA Academia programme. 


\section{Introduction}

Plebiscitarian mechanisms to select candidates and leaders are increasingly popular in electoral democracies (Cross and Pilet 2015). In a sample of 71 parties in 23 democracies circa 2012, Kenig et al. (2015) found that half of the party leaders were elected by inclusive selectorates (members, supporters, both or voters).

A thriving body of research has in recent years examined the causes and/or consequences of party primaries, both in presidential and parliamentary regimes (see Sandri et al. (2015) or Cross et al. (2016) for a presentation of the state of the art). In this paper we focus on the electoral effects of party primaries. For us, party primaries refer to "the internal elections for selecting political leaders or candidates for office (either for parliamentary elections or for chief executive mandates, at all levels) that entail full membership votes (closed primaries), or votes by members, sympathisers and registered voters (open primaries)" (Sandri et al. 2015:11).

According to the primary penalty hypothesis, primaries generate weaker candidates than do other selection mechanisms because they produce ideologically extremist candidates and/or open up internal divisions within parties. According to the primary bonus hypothesis, primary-selected candidates are stronger than those selected by other procedures because primaries bring democratic legitimacy, generate candidates with broad popular appeal, and/or encourage consensus within coalitions of parties that seek to endorse a joint candidate. Finally, it has been suggested that the electoral effect of primaries is contingent on their degree of inclusiveness, their divisiveness and/or the timing of primaries. However, the empirical evidence is mixed at best, and therefore the debate remains open.

In this paper a different venue to making sense of the electoral effects of primaries is explored. While for existing research parties' and citizens' decision-making is not nested, our main argument is that party primary effects entail the interdependence of party procedures for candidate selection. In empirical terms the conventional use of a dummy variable, Primary (Yes/No) is replaced with a dummy variable capturing four different scenarios: (i) none of the main candidates is nominated by primaries; (ii) only the main rivals' candidates are nominated by primaries; (iii) only the own candidate is nominated by primaries; and (iv) none of the main candidates are nominated by them.

Through the analysis of the electoral consequences of primaries we contribute to a century-old debate within the literature about the consequences of the internal organization of political parties, namely the trade-off between intra-party decision 
making and parties' electoral results. According to the classical "iron law of oligarchy", to be effective fighting machines, parties have to be organized along oligarchic rather than "democratic" lines. In Michels' words (1949: 42), "for a party to be able to react with sufficient speed to events and moves by other parties 'a certain degree of cæsarism' is required." However, in a recent paper, Lehrer et al. (2017) show that "democratic" parties [measured as the rank-and-file members' ability to select the party leader] respond more strongly to rival political parties than undemocratic parties due to the information that influences core supporters, who are the same constituency that ultimately influences the policy platforms of democratic parties. When examining the interdependence of parties' procedures for candidate selection, our research will contribute to determine whether the trade-off holds.

Using two different data sets on the branches or wings of 7 national parties in 296 regional elections in Canada, Germany and Spain from 1990 to 2017 and 62 preelection polls in Germany and Spain, the validity of the two approaches is assessed. We show that, other things equal, primary-selected candidates are neither stronger nor weaker than those selected by other procedures. This does not mean, however, that primaries are ineffectual. We find evidence of a penalty for those parties not selecting candidates by primary when their main rival does, in particular when the primary election is not divisive and is held closer to the general election. Finally, we show that those candidates not selected by primaries are more poorly rated than candidates selected by them.

\section{Arguments}

Three competing arguments, primarily relying on evidence from the U.S. primaries experience, have been posited about the effects of primaries on legislative and executive candidates' strength.

First, since the seminal work of Key (1947), the predominant view is the primary penalty hypothesis: primary-selected candidates are weaker in general election competition than candidates selected by other methods. The mechanisms accounting for the hazard of primaries are twofold. Primaries produce candidates who are unappealing to the general electorate because they are selected by the most committed party members who tend to be ideologically distant from the median voter. For instance, Brady et al. (2007) provide evidence supporting this mechanism, while the evidence from Norrander (1989) or kaufmann et al. (2003) goes against. The second mechanism 
argues that the primaries process itself may damage candidates by subjecting their participants to public criticism and opening up internal divisions within parties. This mechanism is supported by Kenney and Rice (1987) or Lengle et al. (1995), but challenged by Atkeson (1998), for instance.

Second, the alternative hypothesis argues that candidates selected by primaries may reap a bonus. The mechanisms accounting for the electoral benefits are again twofold. On the one hand, the primary campaign can allow parties to identify high-quality candidates who will prove to be effective campaigners in the general election (Adams and Merrill 2008). On the other, primaries may be considered demonstrations of intraparty democracy and transparency. As voters usually value this selection mechanism (Young and Cross 2002), they may reward it at the ballot box vis-à-vis nominations emerging from opaque, backroom negotiations (Carey and Polga-Hecimovich 2006).

Finally, we term the third argument the 'contingency approach'. The link between primaries and election outcomes is contingent on institutional and political moderating factors, in particular the degree of inclusiveness, their divisiveness and/or the timing of primaries. The primary penalty might be reduced by opening up the primary elections to non-members (who are closer to the median voter, Kaufmann et al. 2003); when there are few or a single candidate (Lengle et al. 1995); or when primaries are not held close to the general election (Ramiro 2016).

The empirical evidence about the electoral effect of primaries from the few studies using data outside the U.S. is also mixed. Carey and Polga-Hecimovich (2006) and Ramiro (2016) found evidence of a primaries bonus in presidential primaries in Latin America, local primaries in Spain, respectively. However, using data from 111 parties in national elections in 15 countries with parliamentary regimes from 1965 to 2012, Pedersen and Schumacher (2015) found no effect of primaries.

In this paper we explore a different avenue to examine the electoral effects of primaries. Our argument is that their effect on candidate strength entails the interdependence of parties' procedures for candidate selection. The crucial point when estimating primary effects is whether candidates selected by primaries compete against candidates who are also selected by primaries, or against candidates selected by other methods.

Several methodological implications are derived from the interdependence assumption. First, primary effects have to be examined by comparing vis-à-vis the electoral results of those parties entering the election. The simplest situation is when 
only two parties compete, as can be seen in Table 1. In a two-party system there are four possible scenarios when assuming the interdependence of party strategies: none of the parties or both have primary-nominated candidates, only party A's candidate is selected by primaries and only party B's candidate is selected by primaries. In a multipartysystem, the number of possible scenarios is the square of the number of parties entering the election.

Table 1.

Interdependence of Candidate Selection

\begin{tabular}{|c|c|c|c|}
\hline & & \multicolumn{2}{|c|}{ Party B } \\
\hline & & Primary & No primary \\
\hline \multirow{3}{*}{ Party A } & Primary & No effect / & Bonus or penalty \\
\hline & & Moderating factors & \\
\hline & No primary & Bonus or penalty & No effect \\
\hline
\end{tabular}

In the two scenarios in the principal diagonal, the two parties follow the same candidate selection method. All else being equal, when both parties rely on primaries, the potential positive or negative effect of primaries should be mutually cancelled. When relaxing the all-else-being-equal assumption, and therefore the moderating factors come into play, we may observe a different primary bonus (or penalty) for the two parties, even though both rely on primaries to select their candidates. For instance, the primary bonus (or penalty) should be greater for the party whose primaries are held closer to the election. In the scenario where no candidates are selected by primaries, the moderating factors are irrelevant and therefore the candidate selection method does not play any role. In the off-diagonal scenarios, where only one of the parties holds primaries, the expectation about whether primaries have an electoral positive or negative effect is less clear. The party holding primaries should attain a bonus (or a penalty), and the one using other selection mechanism should get a penalty (or a bonus).

However, most of the existing empirical studies do not consider this interdependence of candidate selection methods. They test the primary effect using a dummy variable distinguishing between candidates selected by primaries versus other methods across elections or countries, irrespective of what their rivals do (Pedersen and 
Schumacher 2015). This operationalization based on a decision-theoretic approach (i.e. parties' decision-making is not nested) leads to a biased estimate of the effects of primaries on candidate strength. Two parties competing against each other and not using primaries, and parties not using primaries when their rival does are put together in the ' 0 category'. This is flawed because the candidate selection method of the other party can make a difference to the electoral support of the first party. This problem appears again when putting together in the ' 1 category' primary-selected candidates competing against other primary-selected candidates and primary-selected candidates competing against candidates selected by other procedures.

Estimation bias is not the only problem. In addition, the use of this dummy variable does not allow us to determine which party is attaining a primary bonus (or penalty). If party A's candidate is selected by primaries, while party B's is not, a positive coefficient for the dummy variable means that party A receives more votes than party B. However, it is not possible to know whether the primary-selected candidate attains a bonus, or the candidate not selected by primaries is the one who receives a penalty for not using them, or if both effects take place at the same time. Our point is that if voters value more inclusive selection mechanisms (Young and Cross 2002), they might punish parties that do not select candidates by primaries.

Several scholars have attempted to avoid some of these problems by studying those situations in which only one party holds primaries (Ramiro 2016). This means that if party $\mathrm{A}$ is the one holding primaries, they implicitly study what happens in just the upper- and bottom-right cells of Table 1. But we still do not know whether voters are rewarding (punishing) the party holding primaries, or punishing (rewarding) the party not using them.

Finally, in cases in which more than one party holds primaries, other scholars, such as Carey and Polga-Hecimovich (2006), study whether only one candidate, several, or all candidates in an election are selected by primaries. They study all the cells apart from that in the bottom-left. However, the problem with this procedure is that it is only correct when just two parties compete.

Our second methodological point has to do with the number of degrees of freedom in the analysis. In a pure two-party system, elections are a zero-sum game in which parties compete for a finite number or percentage of votes: Party A's primary affects Party B's support in an inverse way. As all parties (i.e. the 100 per cent of the votes in the election) are grouped together in the 0 or 1 category of the primary dummy, there is 
a single degree of freedom when estimating the coefficient of the primaries variable. Therefore, when observing the election results, it is not possible to determine whether voters reward parties for primaries or punish them for not using inclusive selectorates.

In sum, we contend that, in order to make a non-biased estimate of the effects of primaries on candidates' strength and to identify whether there is a primary bonus or a penalty for using or not using primaries, two methodological decisions are crucial:

- The binary variable (Primary (Yes/No) has to be replaced with a series of dummies capturing the four scenarios in Table 1: (i) none of the candidates of the main parties is nominated by primaries; (ii) only the main rival's candidate is nominated by primaries; (iii) only the own candidate is nominated by primaries; and (iv) both main candidates are nominated by primaries. These series of dummies should be created after matching those parties competing against each other in the specific elections. In our empirical analysis we will focus on the two main national parties and will control for whether any other parties have used primaries. It is not possible to run the models if we include all parties in every election and consider all the possible scenarios combining the use or not of primaries across parties due to the lack of observations: given the still-low proportion of candidates selected by primaries, we would have numerous empty cells if studying all possible combinations in situations where more than two parties compete.

- The number of degrees of freedom when estimating the primary effect has to be greater than 1. This means that more than two parties in the corresponding elections have to be studied (i.e. when there are more than two parties competing, it is a zero-sum game for all of them together, but not for every pair of parties considered) or, if only two are studied, they must not have the 100 per cent of the votes together.

In the empirical analysis our interdependence approach will be compared vis-à-vis the decision-theoretic approach, using parties' vote shares in regional elections as the dependent variable. The discussion of how primaries affect candidate strength leads us to formulate two conflicting hypotheses. First, according to the decision theoretic approach, primary elections will affect election results irrespective of how the candidates of rival parties are selected. However, according to our interdependent decision-making approach, primary elections will affect election results when only one party holds primaries." 


\section{Data and Methods}

We have collected information from all regional elections in three parliamentary and multilevel countries, Canada, Germany and Spain, from 1990 (when membership ballots started to be used to select either the 'candidate' for the chief executive office and/or the party leader) until 2017. In the three countries closed and party-regulated primaries are employed. In contrast with state-regulated primaries, when primaries are party-regulated the four scenarios in our interdependence approach emerge given that the decision-making process to select leaders is in the hands of parties. In addition, these three countries have multiparty systems and this is also crucial in order to have more than one degree of freedom when estimating the coefficient of the primaries variable. We focus on regional elections in only three countries instead of on national elections in many countries in order to increase the number of observations while maximizing the control of institutional, cultural and idiosyncratic factors (Cross et al. 2016). The three countries represent established parliamentary democracies with a very high degree of economic and political decentralization. According to the Regional Authority Index elaborated by Hooghe et al. (2016), in 2010 Germany was the most decentralized country in a sample of 80 countries, Spain was second and Canada eighth. In sum, the value of the regional office is largely similar across the three countries.

Finally, given that in Germany and Spain primaries are still not used to select legislative candidates, we focus on 'executive candidates'. Strictly speaking, in parliamentary regimes no 'candidate' runs in a popular election to become the head of a government in the same way as presidential or gubernatorial candidates in presidential and semi-presidential regimes. Prime ministers are elected by parliaments, not directly by citizens. In practice, however, the trend towards the 'presidentialization' of authority in many parliamentary democracies (Poguntke and Webb 2005) implies that parties inform voters prior to the election of their 'top candidate' (also referred to as 'electoral leader') and the future prime minister if they reach the majority in Parliament. Parties differ in the precise process of selecting their 'top candidate', however. In Canada, as is typical of Anglo-Saxon democracies (Cross et al. 2016), the 'party leader' is by default their 'top candidate' for the upcoming election. In contrast, in Germany and Spain, as is common in continental Europe, the selection of the 'party leader' and the 'top candidate' are formally separated in two different processes (Astudillo 2015). Therefore, in Germany and Spain we focus on the latter selection. ${ }^{1}$ 
In order to make comparable analyses we collected data in every region in the three countries. In Germany and Spain we selected the two most voted national party branches in the whole period 1990-2017. In the former we focused on the right-wing Christlich Demokratische Union (CDU) ${ }^{2}$ and the left-wing Sozialdemokratische Partei Deutschlands (SPD), while in the latter we focus on the right-wing Partido Popular (PP) and the left-wing Partido Socialista Obrero Español (PSOE). In Canada, the rule is slightly different. The federal New Democratic Party (NDP) has wings in almost all provinces, the Liberals (LP) in just four, whereas the rest of provincial Liberal parties operate as separate entities, and the Conservative party of Canada (CPC) has no formally provincial wings. Still these separate provincial Liberal and Conservative parties are distinctive from ethno-regional parties, such as the Parti Quebecois, and are ideologically linked with the federal parties. As a result, we have included the provincial Liberal and Conservative parties no matter their formal affiliation to the federal parties. Finally, in three provinces (British Columbia, Manitoba and Saskatchewan) the branches of the NDP replace either the provincial Liberal or Conservative party as one of the two most voted parties considering the whole studied period. In congruence with existing research on the electoral effect of primaries, we focus only on national parties (and not in the main ethno-regional subnational parties when these parties compete) in order to have a single dimension of competition.

The branches and wings of these seven national parties have opened up the process of selecting their aspirants to the chief executive office through the one-member-onevote method (OMOV) in Canada, the 'members' survey' ('Mitgliederbefragung') in Germany, and the primaries (Primarias) in Spain. To explore the robustness of our results, our models will also be estimated excluding, first, the observations from Canada due to its particularities and, second excluding those regional elections in the three countries in which the two main national parties (CDU, SPD, PP, PSOE, CPC and LP) were not the two largest.

The data include, therefore, branches or wings of 7 national parties in 296 elections in 42 regions ( 9 'Provinces' in Canada, ${ }^{3} 16$ 'Länder' in Germany and 17 'Comunidades Autónomas' in Spain) in the descriptive analyses and 282 elections in the regressions due to the availability of information included in the data. There are four interesting patterns. First, movement towards primaries greatly differs across countries. They are much more used in Canada than in Spain and especially Germany. Second, not all parties are equally prone to selecting their candidates through primaries. Third, the use 
of primaries across regions within countries is surprisingly diverse. For instance, the 22 primaries held by the SPD in Germany have taken place in only seven Länder. Finally, primaries are not invariably a one-way street. Some parties have experimented with primaries and then dropped the practice in subsequent elections. For instance, the PSOE in Spain did not use primaries between 2003 and 2011.

Table 2.

Use of 'Primaries' by the Main National Parties in Regional Elections in Canada, Germany and Spain*

\begin{tabular}{|c|c|c|c|c|c|}
\hline Country & \# Elections & Party & \# Primaries & $\begin{array}{c}\text { Year of elections with } \\
\text { primaries }\end{array}$ & $\begin{array}{c}\text { \# Regions } \\
\text { with primaries }\end{array}$ \\
\hline \multirow{3}{*}{ Canada } & \multirow{3}{*}{64} & Conservatives & 15 & $\begin{array}{c}1990,1993(2), 1995, \\
1998,2003,2007(2), \\
2008,2010,2011,2012 \\
2015(2), 2017\end{array}$ & 8 \\
\hline & & Liberals & 20 & $\begin{array}{c}\text { 1993, 1995(2), 1996(2), } \\
\text { 1997, 1998, 1999(2), } \\
\text { 2001, 2003(2), 2004, } \\
\text { 2006, 2012, 2013, } \\
\text { 2014(2), 2015, 2016 }\end{array}$ & 8 \\
\hline & & NDP** & 5 & $\begin{array}{c}2003,2011,2013,2016, \\
2017\end{array}$ & 2 \\
\hline \multirow[t]{2}{*}{ Germany } & \multirow[t]{2}{*}{107} & $\mathrm{CDU}$ & 5 & $\begin{array}{c}1995,2006(2), 2012, \\
2016\end{array}$ & 3 \\
\hline & & SPD & 12 & $\begin{array}{c}1995,1998,1999(3) \\
2001,2007,2009,2011 \\
2012,2013,2016\end{array}$ & 7 \\
\hline \multirow[b]{2}{*}{ Spain } & \multirow[b]{2}{*}{125} & PP & 2 & 2011,2015 & 1 \\
\hline & & PSOE & 22 & $\begin{array}{c}1998,1999(7), 2003 \\
2011(3), 2015(7), 2016 \\
(2), 2017\end{array}$ & 12 \\
\hline
\end{tabular}

*In parentheses, the number of primaries when there is more than one in a given year.

** The data for the NDP only come from the three provinces included in the analysis (British Columbia, Manitoba and Saskatchewan).

Each observation in our data is a party branch or wing in a given election. Our dependent variable is the percentage of the vote won by the party in the regional election, Vote \%t. Following Carey and Polga-Hecimovich (2006, 535-536), and in order to account for the party's baseline strength, we control for the percentage of vote won by the party in the previous election, Vote $\%$ t-1. We also include the following controls capturing current regional electoral tides:

- Incumbent Party: A dummy coded 1 if the party controlled the head of the regional government; 0 otherwise.

- Unemployment Rate Change: To capture how the region is doing, we select the difference in the number of unemployed people as a percentage of the labour force 
in the two election years in every region. ${ }^{4}$ More specifically, the two unemployment rates are measured in the quarters in which the elections were held.

- Unemployment Rate Change*Incumbent Party: An interactive variable to identify the marginal effect of economic performance on the candidate of the incumbent party. As a decrease in the unemployment rate change should help the party in power, we expect a negative coefficient of the interactive term.

- Country dummies capturing idiosyncratic, unobservable factors. ${ }^{5}$

- Third Party Primary: Given that in the three countries there are more than two parties competing in elections, we will also control for a dummy variable coded 1 if in a given election any party apart from the two main national parties used primaries, 0 , otherwise.

Finally, we measure the key independent variable, whether the candidate was selected by primaries, in two different ways. First, we follow the decision-theoretic approach and use a dummy variable, Primary (Yes/No), coded 1 when the candidate is selected by primaries; 0 otherwise. Second, following our interdependent decision approach, we include a series of dummies to distinguish three scenarios: neither of the two 'main' candidates is nominated by primaries (0), only the 'main' rival's candidate is nominated by primary (1), only the own candidate is nominated by primary (2). Due to the very low number of cases in which both 'main' candidates are nominated by primaries - only eight in total - this category is excluded from the estimates. ${ }^{6}$ The reference category is none of the candidates is nominated by primaries. The information on primaries comes from different sources: parties' websites, newspapers, party documents and press, politicians' biographies, and published studies on parties and regional elections (Astudillo and Detteberck 2018; Cross 1996; Young and Cross 2002).

We also explore the divisive-primary hypothesis and the timing effect of primaries (i.e. whether the temporal proximity of primaries to the legislative election makes a difference). The degree of openness is not examined as only members are in the selectorates. The divisive-primary hypothesis is tested using the number of primary candidates and the primary winner's vote share. The timing effect of primaries is captured with the temporal proximity of primaries and regional elections using Days (i.e. actual primary election and general election dates) as the unit. The variable ranges from 65 (i.e. the primaries were held two months before the regional election) to 1,456 (i.e. almost four years since the primary election and the general election). We include 
the number of days and its square to account for a possible non-linear effect. The descriptive statistics of the variables are displayed in Table 3.

Table 3. Descriptive Statistics

\begin{tabular}{l|c|c|c|c|c}
\hline Variable & Obs & Mean & Std. Dev. & Min & Max \\
\hline Vote \%t & 553 & 34.88 & 11.82 & 0.6 & 69.6 \\
\hline Vote \%t-1 & 553 & 35.92 & 11.65 & 0.6 & 69.6 \\
\hline Incumbent Party & 553 & 0.43 & 0.50 & 0 & 1 \\
\hline Unemployment Rate Change & 553 & -0.41 & 1.81 & -5.66 & 11.42 \\
\hline Other Party Primary & 530 & 0.12 & 0.33 & 0 & 1 \\
\hline Number of Primary Candidates & 61 & 2.97 & 1.70 & 1 & 9 \\
\hline Primary Winner's Vote Share & 61 & 61.85 & 11.62 & 38.5 & 99 \\
\hline Days & 64 & 518.80 & 319.05 & 65 & 1456 \\
\hline Primary (Yes/No) & & & & & \\
Canada & 123 & 0.28 & 0.45 & 0 & 1 \\
Germany & 186 & 0.09 & 0.297 & 0 & 1 \\
Spain & 244 & 0.09 & 0.30 & 0 & 1 \\
\hline Primary Dummies & & & & & \\
Canada & 116 & 0.83 & 0.95 & 0 & 3 \\
Germany & 186 & 0.27 & 0.62 & 0 & 2 \\
Spain & 244 & 0.29 & 0.66 & 0 & 3 \\
\hline \multicolumn{5}{|l}{} \\
\end{tabular}

\section{Results}

In Figure 1, the relationship between electoral performance (i.e. the difference between the vote share of parties in two consecutive elections in t and t-1) and the use of primaries in to select the top candidate in our sample is displayed. The conclusion is that what matters is what the main rival does, not what you do. At first glance, no differences exist between selecting the top candidate through primaries or not when your main competitor does not. When neither party holds primaries $(\mathrm{N}=425)$, the median electoral performance is -0.3 and the mean -0.7 ; when a party uses primaries but its main competitor does not (the 'the own party' category, $\mathrm{N}=65$ ) the median is -0.1 and the mean 0.2. However, not using primaries to select your top candidate when your main competitor does (the 'the other party' category, $\mathrm{N}=64$ ) is punished at the ballot box with about 3.5 points fewer (the median in 3.5 and the mean 3.3). 


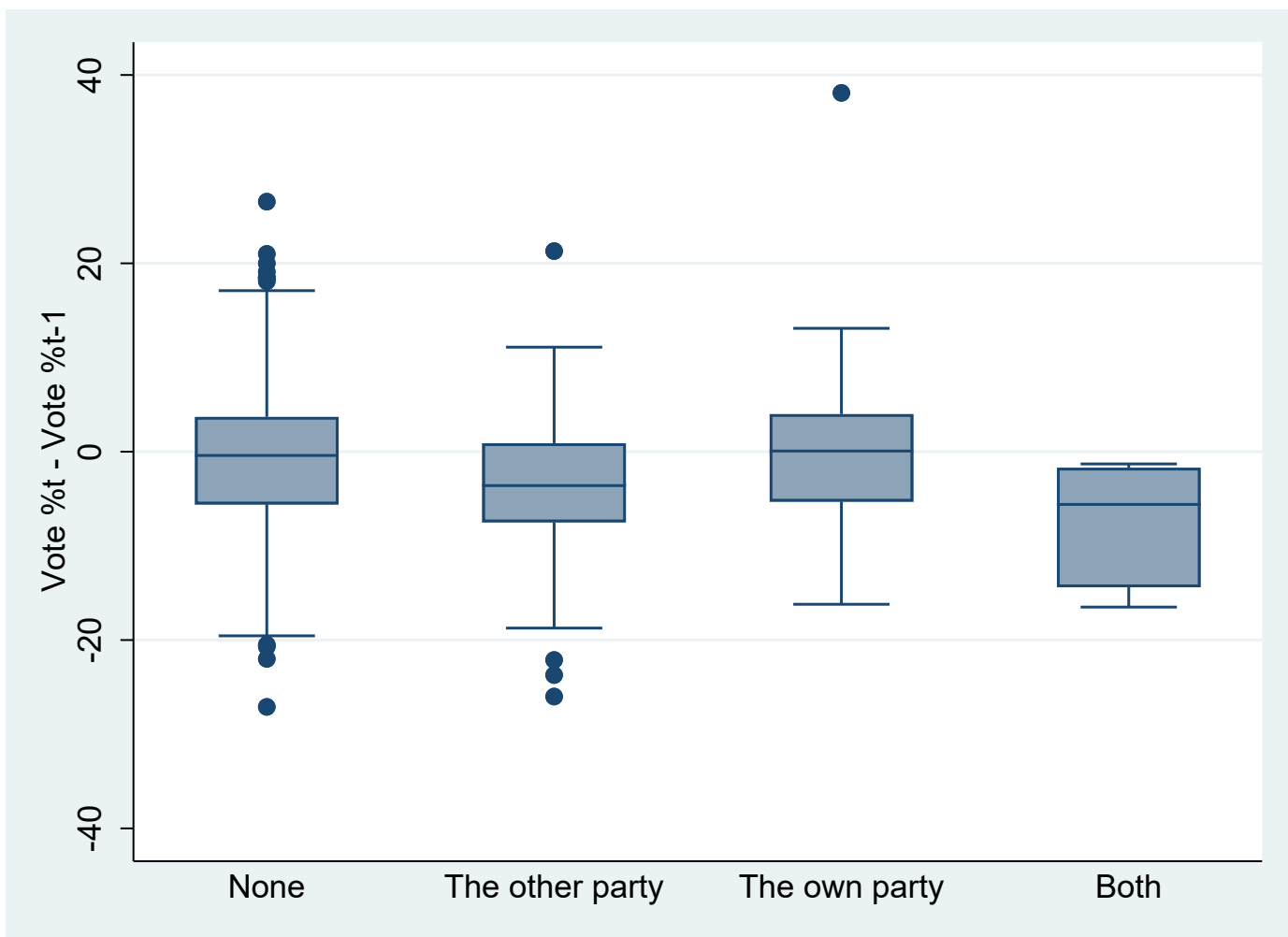

Figure 1. Effects of Primary Election on Share of Vote.

In Table 4 we examine whether the selection of top candidates through primaries makes a difference for the electoral performance of parties using a mean comparison test. First, on the left-side of the table we test the effect of primaries following the conventional approach. As can be seen, there are not statistically significant differences in the election results of parties depending on whether primaries are used or not. The averages are respectively -1.1 and -1.0 . In other words, when the analysis of primaries is rendered blind to the behaviour of competitors, primaries are inconsequential. On the right-side of the table we test the electoral effect of primaries when considering the behaviour of the 'main' competitors. In each cell the comparison is with the 'No Primaries' scenario. There is a statistically significant punishment at the 0.01 per cent level for a party when it does not use primaries but its 'main' rival does (the 'the rival party' category) in comparison with the scenario in which none does. However, if the rival's top candidate is not selected using primaries, the election results of a given party do not change depending on whether it uses primaries or not (the 'the own party' category, $\mathrm{p}=0.39$ ). 
Table 4. Mean Comparison Tests

\begin{tabular}{l|c|c|c|c|c|c}
\hline & \multicolumn{2}{|c|}{$\begin{array}{c}\text { Decision-theoretic } \\
\text { approach }\end{array}$} & \multicolumn{4}{c}{ Interdependence approach } \\
& $\begin{array}{c}\text { No } \\
\text { primaries }\end{array}$ & Primaries & $\begin{array}{c}\text { No } \\
\text { primaries }\end{array}$ & $\begin{array}{c}\text { Primaries only in } \\
\text { the rival party }\end{array}$ & $\begin{array}{c}\text { Primaries only } \\
\text { in the own party }\end{array}$ & $\begin{array}{c}\text { Primaries in } \\
\text { both parties }\end{array}$ \\
\hline Average & -1.03 & -1.05 & -0.71 & -3.31 & 0.15 & -8.83 \\
Std. dev. & $(7.73)$ & $(8.20)$ & $(7.56)$ & $(8.48)$ & $(7.82)$ & $(6.98)$ \\
N & 494 & 75 & 425 & 64 & 65 & $\mathrm{t}$ \\
\hline & & $\mathrm{t}=0.01$ & $\mathrm{t}=2.52$ & $\mathrm{p}=0.01$ & $\mathrm{p}=0.39$ & $\mathrm{p}=0.00$ \\
\hline
\end{tabular}

In Table 5 the effect of primaries on election results is examined through an OLS regression in which the controls are included. Although the structure of the data is clearly hierarchical (by country, region and election), we have decided against running a multilevel model. According to Bryan and Jenkins (2016, 19-20) based on Monte Carlo simulations, multilevel models require 25 countries for linear models at the very minimum, and most likely more for models with a specification other than a relatively basic one. As there are only three countries, with 9 provinces in Canada, 16 Länder in Germany and 17 Comunidades Autónomas in Spain in the sample, the standard errors have been clustered by election to account for non-independence in the data structure and to match parties competing against each other in the specific election.

The first model tests the conventional wisdom assuming the decision-theoretic approach, while the remaining models test our approach allowing the interdependence of party decisions. When following the conventional approach, Vote $\%$ t-1 is naturally a strong predictor of partisan support in t. The coefficients on the subsequent three variables should be interpreted in conjunction. The negative coefficient on Incumbent Party is by itself an estimate of the effect of being the candidate from an incumbent party that has ruled over no change in the unemployment rate. The variable is not statistically significant. Similarly, the coefficients on Unemployment Rate Change and Unemployment Rate Change*Incumbent Party are not significant, indicating that candidates from incumbent parties are not rewarded (punished) for good (bad) economic performance. The most interesting result is that the candidate selection by primaries does not significantly affect the vote share of parties. In other words, nomination by primaries is not an electoral asset. 
The second model is identical to the first, except that the binary dummy, capturing whether the candidate is selected by primaries or not, is replaced with a categorical variable distinguishing among three scenarios: none of the main parties have primary-nominated candidates (the reference category); a given party, but not the rival, has nominated its candidate by primaries (Only the own party); and the rival, but not the given party, has nominated its candidate via a primary (Only the rival party). The model shows little change in the coefficients of the control variables. Our most important result is the strong negative effect of not selecting the candidate by primaries when the rival does based on vote share. Other things being equal, primaries only in the other party generate a penalty of 3.2 points and the estimate is significant at the 0.01 per cent level. However, nomination by primaries does not generate a bonus: candidates selected by primaries do not run more strongly than those selected by other methods when the rival's candidate selection is not by primaries. In sum, the effect of primaries is driven by what the rival does. We do not find evidence of a primary bonus, but of a primary penalty when only the rival's candidate is selected by primaries.

In models 3, 4, 5 and 6 we explore the robustness of our findings. In the third model we control for whether third parties are using primaries. We have included a variable capturing whether at least any other party uses primaries (Third party primary). The models produces a smaller coefficient on Only the own party and Only the rival party, but their statistical significance does not change. Interestingly, when one other parties apart from the two main national branches use primaries, the support for these branches drops. This is clearly in line with our previous models showing that the effect of primaries is driven by what the other parties do. The fourth model, which adds to the third an interaction term between our primary categorical variable and whether other parties used primaries, shows that national parties are punished by primaries in other parties when the former do not select candidates by this method: this interaction term is negative and statistically significant at the 0.05 per cent level. However, if national parties use primaries, they are not affected by their use in other parties: the interaction is far from being statistically significant. The fifth model replicates the first one, but excluding observations from Canada, as explained. As can be seen, the results are qualitatively the same: primaries only in the other national party generates a statistically significant penalty (at the 0.05 per cent level), while nomination by primaries does not generate a bonus. Finally, in the last model, when excluding those elections in which the national parties we have selected are not the two largest, the results remain qualitatively 
the same. The coefficient on Only the other party is again negative and statistically significant at the 0.05 per cent level, while the coefficient on Only the own party is not statistically significant.

Table 5. Effects of Primary Election on Share of Vote

\begin{tabular}{|c|c|c|c|c|c|c|}
\hline & Decision-theoretic & \multicolumn{5}{|c|}{ Interdependence approach } \\
\hline & Model 1 & Model 2 & Model 3 & Model 4 & Model 5 & Model 6 \\
\hline Vote $\% 0_{t-1}$ & $\begin{array}{c}0.78 * * * \\
(0.04)\end{array}$ & $\begin{array}{c}0.76^{* * *} * \\
(0.04)\end{array}$ & $\begin{array}{c}0.76^{* * *} \\
(0.04)\end{array}$ & $\begin{array}{l}0.76^{* * * *} \\
(0.04)\end{array}$ & $\begin{array}{c}0.78 * * * \\
(0.04)\end{array}$ & $\begin{array}{c}0.58 * * * \\
(0.06)\end{array}$ \\
\hline Incumbent Party & $\begin{array}{l}-0.22 \\
(0.98)\end{array}$ & $\begin{array}{c}0.50 \\
(1.00)\end{array}$ & $\begin{array}{c}1.02 \\
(0.96)\end{array}$ & $\begin{array}{c}0.99 \\
(0.96)\end{array}$ & $\begin{array}{c}1.49 \\
(1.03)\end{array}$ & $\begin{array}{c}2.19 * * \\
(1.07)\end{array}$ \\
\hline Unemployment Rate Change & $\begin{array}{c}0.08 \\
(0.21)\end{array}$ & $\begin{array}{l}-0.04 \\
(0.21)\end{array}$ & $\begin{array}{l}-0.08 \\
(0.21)\end{array}$ & $\begin{array}{l}-0.08 \\
(0.20)\end{array}$ & $\begin{array}{l}-0.15 \\
(0.21)\end{array}$ & $\begin{array}{c}0.20 \\
(0.28)\end{array}$ \\
\hline Unemployment*Incumbent Party & $\begin{array}{l}-0.28 \\
(0.37)\end{array}$ & $\begin{array}{l}-0.32 \\
(0.37)\end{array}$ & $\begin{array}{l}-0.35 \\
(0.36)\end{array}$ & $\begin{array}{l}-0.34 \\
(0.35)\end{array}$ & $\begin{array}{c}0.05 \\
(0.34)\end{array}$ & $\begin{array}{l}-0.42 \\
(0.48)\end{array}$ \\
\hline Spain & $\begin{array}{c}0.99 \\
(0.57)\end{array}$ & $\begin{array}{l}1.10^{* *} \\
(0.57)\end{array}$ & $\begin{array}{c}1.95 * * * \\
(0.53)\end{array}$ & $\begin{array}{l}1.97 * * \\
(0.53)\end{array}$ & $\begin{array}{l}1.21 * * \\
(0.56)\end{array}$ & $\begin{array}{c}2.33 * * * \\
(0.63)\end{array}$ \\
\hline Canada & $\begin{array}{c}2.33 * * * \\
(0.84)\end{array}$ & $\begin{array}{c}3.16^{* * *} * \\
(0.86)\end{array}$ & $\begin{array}{c}3.98 * * * \\
(0.88)\end{array}$ & $\begin{array}{c}3.92 * * * \\
(0.88)\end{array}$ & & $\begin{array}{c}4.38 * * * \\
(1.04)\end{array}$ \\
\hline Primary (Yes/No) & $\begin{array}{l}-1.41 \\
(1.06)\end{array}$ & & & & & \\
\hline Primaries (ref. None of them) & & & & & & \\
\hline Only the own party & & $\begin{array}{l}-0.86 \\
(1.00)\end{array}$ & $\begin{array}{l}-0.39 \\
(1.01)\end{array}$ & $\begin{array}{l}-1.18 \\
(0.95)\end{array}$ & $\begin{array}{l}-1.59 \\
(1.03)\end{array}$ & $\begin{array}{l}-0.89 \\
(1.19)\end{array}$ \\
\hline Only the rival party & & $\begin{array}{c}-3.19 * * * \\
(1.12)\end{array}$ & $\begin{array}{c}-2.80 * * * \\
(1.03)\end{array}$ & $\begin{array}{l}-1.63 \\
(1.08)\end{array}$ & $\begin{array}{c}-2.47 * * \\
(1.24)\end{array}$ & $\begin{array}{c}-2.85^{* *} \\
(1.41)\end{array}$ \\
\hline Third party primary & & & $\begin{array}{c}-5,23 * * * \\
(0.92)\end{array}$ & $\begin{array}{c}-4.87 * * * \\
(1.12)\end{array}$ & & \\
\hline Only the own party*Third party primary & & & & $\begin{array}{c}3.85 \\
(3.55)\end{array}$ & & \\
\hline Only the other party*Third party primary & & & & $\begin{array}{c}-5.75^{* *} \\
(2.33)\end{array}$ & & \\
\hline Constant & $\begin{array}{c}6.34 * * * \\
(1.32)\end{array}$ & $\begin{array}{c}6.61 * * * \\
(1.30)\end{array}$ & $\begin{array}{c}6.65^{* * *} \\
(1.19)\end{array}$ & $\begin{array}{c}6.49 * * * \\
(1.15)\end{array}$ & $\begin{array}{c}5.56 * * * \\
(1.24)\end{array}$ & $\begin{array}{c}12.93 * * * \\
(2,12)\end{array}$ \\
\hline $\mathrm{R}^{2}$ & 0.61 & 0.62 & 0.65 & 0.66 & 0.66 & 0.49 \\
\hline $\mathrm{N}$ & 553 & 538 & 530 & 530 & 428 & 384 \\
\hline \# Clusters & 282 & 272 & 268 & 268 & 217 & 194 \\
\hline
\end{tabular}

Standard errors in parentheses.

$* * * \mathrm{p}<0.01, * * \mathrm{p}<0.05$

Finally, in Table 6 we have selected the 64 elections in which only the rival's candidate is selected by primaries to explore the divisive-primary hypothesis and the timing effect of primaries. ${ }^{7}$ We expect that the penalty for the party not using primaries should decrease with a greater number of primary candidates and/or a lower electoral support for the primary winner. Similarly, we expect that primaries held in temporal proximity to elections increase the penalty. In the first model, the number of primary 
candidates has the expected positive sign (the more primary candidates, the lower the penalty) and is statistically significant at the 0.05 per cent level, while the primary winner's vote share does not significantly affect the penalty. In the second model we find evidence that the timing of primaries makes a difference. The more (less) temporally proximate are primaries and the election, the greater (lower) the penalty. ${ }^{8}$ Both Days to Election and Days to Election ${ }^{2}$ are statistically significant at the 0.1 and 0.05 per cent level respectively. Finally, the third model, which combines the regressors from the first two, does not substantially change the results: the number of primary candidates is now statistically significant at the 0.01 per cent level, while the statistical significance of the primary winner's vote share and the timing of primaries does not change. The only statistically significant control in the three models is Vote \%t-1.

Table 6. Effect of Types of Primary Election on Share of Vote

\begin{tabular}{|c|c|c|c|}
\hline & Model 1 & Model 2 & Model 3 \\
\hline Vote $\%{ }_{t-1}$ & $\begin{array}{c}0.76 * * * \\
(0.13)\end{array}$ & $\begin{array}{c}0.79 * * * \\
(0.13)\end{array}$ & $\begin{array}{c}0.72 * * * \\
(0.14)\end{array}$ \\
\hline Incumbent Party & $\begin{array}{c}1.90 \\
(3.98)\end{array}$ & $\begin{array}{c}1.94 \\
(4.09)\end{array}$ & $\begin{array}{c}4.23 \\
(4.31)\end{array}$ \\
\hline Unemployment Rate Change & $\begin{array}{c}0.54 \\
(1.03)\end{array}$ & $\begin{array}{c}0.31 \\
(0.95)\end{array}$ & $\begin{array}{c}0.39 \\
(1.05)\end{array}$ \\
\hline Unemployment*Incumbent Party & $\begin{array}{l}-1.17 \\
(1.47)\end{array}$ & $\begin{array}{l}-1.27 \\
(1.29)\end{array}$ & $\begin{array}{l}-1.22 \\
(1.46)\end{array}$ \\
\hline Spain & $\begin{array}{l}-0.87 \\
(2.85)\end{array}$ & $\begin{array}{l}-0.81 \\
(2.79)\end{array}$ & $\begin{array}{l}-0.23 \\
(2.82)\end{array}$ \\
\hline Canada & $\begin{array}{l}-3.38 \\
(2.79)\end{array}$ & $\begin{array}{l}-1.15 \\
(2.22)\end{array}$ & $\begin{array}{l}-3.69 \\
(2.53)\end{array}$ \\
\hline \# of Candidates & $\begin{array}{l}1.57 * * \\
(0.70)\end{array}$ & & $\begin{array}{c}1.87 * * * \\
(0.61)\end{array}$ \\
\hline Primary Winner's Vote Share & $\begin{array}{l}-0.005 \\
(0.091)\end{array}$ & & $\begin{array}{c}0.03 \\
(0.08)\end{array}$ \\
\hline Days to Election & & $\begin{array}{l}-0.026^{*} \\
(0.014)\end{array}$ & $\begin{array}{c}-0.034 * * \\
(0.013)\end{array}$ \\
\hline Days to Election ${ }^{2}$ & & $\begin{array}{c}0.00002 * * * \\
(0.00000)\end{array}$ & $\begin{array}{c}0.00002 * * * \\
(0.00000)\end{array}$ \\
\hline Constant & $\begin{array}{c}2.28 \\
(7.78)\end{array}$ & $\begin{array}{c}8.95 \\
(6.05)\end{array}$ & $\begin{array}{c}5.74 \\
(8.83)\end{array}$ \\
\hline $\mathrm{R}^{2}$ & 0.70 & 0.75 & 0.75 \\
\hline $\mathrm{N}$ & 60 & 64 & 60 \\
\hline
\end{tabular}

\section{Endogeneity and simultaneity}

A major concern when examining the electoral effects of primaries is that their presence is endogenous to anticipated voter support. We do not see reasons to think that expectations about election results drive the decision to hold primaries. First, previous 
research (Carey and Holga-Hecimovich 2006; Ramiro 2016) empirically examining the issue has found no evidence of endogeneity. Second, primaries are exceptional in some parties included in the sample. The PP in Spain has only held two and the CDU in Germany only five. However, the variability of the electoral support of the two parties (the standard deviations are respectively 14.44 and 9.38) is similar to that of their rivals, the PSOE and the SPD (respectively 10.65 and 10.26). Third, our main finding is that the effect of primaries is driven by what the rival does and this clearly goes against endogeneity. In other words, the negative electoral externalities created by primaries are not compatible with an endogeneity problem.

Similarly, we think that there is no reason to suspect that a simultaneous relationship exists between the methods for selecting candidates used by parties in every country. Again, in both Germany and Spain the huge difference between the number of primaries held by the CDU and the SPD (5 versus 12) and the PP and the PSOE (2 versus 22) clearly indicates that party strategies are not simultaneously determined.

\section{Testing the causal mechanism with survey data}

Using our second data set, we examine whether primary-selected candidates are more favourably evaluated than candidates selected by other procedures. This is the causal mechanism accounting for the punishment when a given party is not using primaries but its main rival does. Owing to the availability of data, we focus on 21 primary-selected candidates in regional elections in Spain (20 from the PSOE and 1 from the PP) and 10 in Germany ( 7 from the SPD and 3 from the CDU). We compare their ratings using an 11-point scale ranging from 0 (dislike) to 10 (like) in Spain and -5/+5 scale in Germany. In both countries the data come from the corresponding pre-election surveys. In Germany we rely on telephone interviews conducted by the Mannheimer Forschungsgruppe Wahlen, while in Spain, the surveys are face-to-face and were conducted by the Centro de Investigaciones Sociológicas.

In Figure 2, we compare how the ratings of primary-selected candidates in the election held in $t$ but by other procedures than in the election held in $t-1$ differ from the ratings of candidates selected by other procedures in the two elections. According to the results of the previous analysis, we expect that the ratings of the former should increase, while the ratings of the latter should diminish. As expected, the median for the primaryselected candidates is positive, 0.15, while the median for the latter is negative, -0.2 . The median difference is greater for the group of candidates not selected by primaries. 


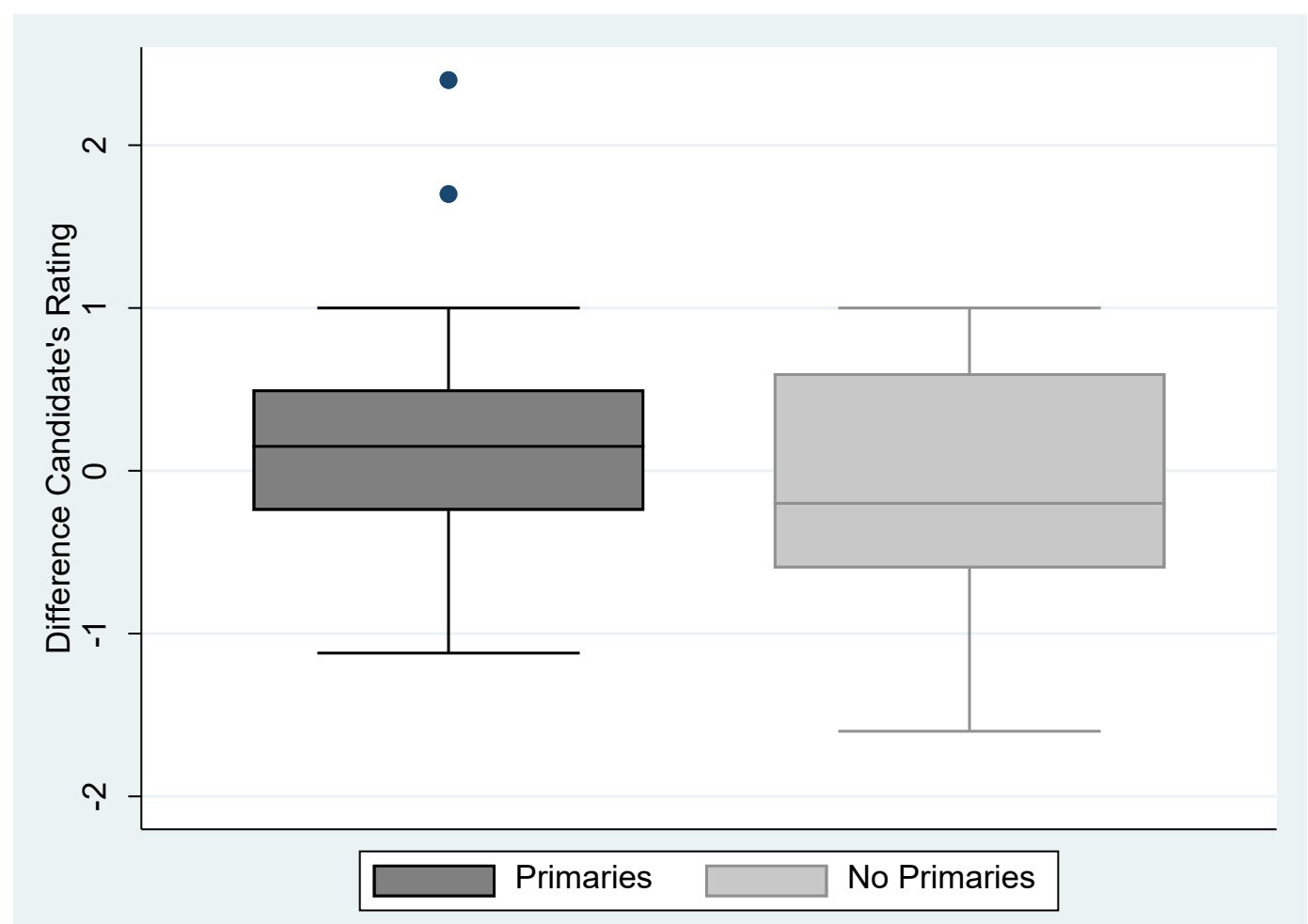

Figure 2. Effects of Primary Election on Candidates' Ratings.

In Table 7 we test whether the difference in the ratings between the two consecutive elections is statistically different between the two groups of candidates. As can be seen, according to the paired mean comparison test, the difference 0.36 is statistically at the 0.05 per cent level (more precisely at the 0.017 per cent level). In sum, primaries make a difference both for primary-selected candidates and for those selected by other procedures.

Table 7. Mean Comparison Test

\begin{tabular}{l|c|c}
\hline & \multicolumn{2}{|c}{ Candidates' rating } \\
\hline & Primaries & No Primaries \\
\hline Average & 0.183 & -0.180 \\
Std. dev. & 0.125 & 0.135 \\
$\mathrm{~N}$ & 31 & 31 \\
\hline Difference & \multicolumn{2}{|c}{0.363} \\
$\mathrm{P}$ & \multicolumn{2}{|c}{0.017} \\
\hline
\end{tabular}




\section{Conclusion}

The implicit assumption of most existing empirical research about the electoral consequences of primaries is that there are no other parties selecting candidates at the same time. A binary dummy capturing whether candidates are selected by primaries or through other methods is therefore sufficient to estimate the electoral effect of this selection method. When moving from a decision-theoretic to an interdependent decision-making process approach, four different scenarios emerge: none of the candidates is nominated by primaries, only the rival's candidate is nominated by primaries, only the own candidate is nominated by primaries, and both candidates are nominated by primaries. These have not been systematically examined in existing research. A second shortcoming of the literature we have highlighted is the problem of degrees of freedom when estimating the effect of primaries. As the binary variable renders election results a zero-sum game, it is not possible to know whether the primary-selected candidate receives a bonus, or the candidate not selected by primaries receives a penalty for nor using them, or both effects are at play at the same time.

Relying on original data from the branches and wings of 7 national parties and 296 regional elections in three parliamentary regimes, Canada, Germany and Spain, we found no evidence that, other things being equal, primary-selected candidates are stronger than those selected by other procedures, as some other empirical studies have already found (Pedersen and Schumacher 2015). This does not mean, however, that primaries are ineffectual. There is evidence of a penalty for those parties not selecting candidates by primaries when the main rival does, in particular the lower the number of primary candidates and the closer the temporal proximity between the primaries and the general election. In addition, the data from 62 pre-election polls in Germany and Spain show that satisfaction with candidates not selected by primaries drops when the main rival party in the election uses this selection method.

Our finding has several implications for the century-old debate about intra-party decision making and parties' electoral results. First, contrary to the 'Michellian' vision, opening up the internal decision making does not entail an electoral penalty. The Michelian argument used by parties to justify not using primaries (Ramiro 2016) is not supported by our evidence. However, primaries are not necessarily an electoral asset as Carey and Polga-Hecimovich (2006) argue in presidential regimes. When assessing the electoral effects of internal reforms, such the introduction of primary elections to select leaders, parties should be studied as actors making interdependent decisions. 
Several limitations of our empirical analysis are important to be aware of. The first limitation is that only three parliamentary countries using closed and party-regulated primaries are included in our sample. These characteristics may limit the generalizability of our results. Clearly, the extent to which our findings can be extrapolated to other contexts deserves more attention: we require more studies supporting our results. Perhaps this effect is inherent to parliamentary regimes and party-based politics (Samuels and Shugart 2010). The next step would be to compare primaries in presidential and parliamentary systems. The second limitation results from the methodology. Although the structure of the data is hierarchical (i.e., we are examining the intra-party decision-making process of national parties in regional elections in specific years), regional elections are considered as independent observations. The logic behind this assumption is that regional offices are very valuable in the three countries due to the very high degree of decentralization. However, party strategies in two regions within the same country are more highly correlated than party strategies in two regions from different countries and this may affect our estimates. In our estimates we have simply clustered the standard errors by election to account for non-independence in the data structure and to match parties competing against each other in the specific election. Our interdependence approach to primaries cries out for methods of data analysis that properly model interdependence. Spatial econometric models (Williams 2015), for instance, are interesting ways to model the patters of spatial interdependence of parties. A substantial number of countries and elections should be included in the sample in order to employ methods modelling interdependence. 


\section{References}

Adams J and Merrill III S (2008) Candidate and Party Strategies in Two-Stage Elections Beginning with a Primary. American Journal of Political Science 52: 344-359.

Astudillo J (2015) Losers' Second Chances and Control of the Party Machine: Aspirant Premiers in Regional Spain. South European Society and Politics 20: 181-200.

Astudillo J and Detterbeck K (2018) Why, sometimes, primaries? Intraparty democratization as a default selection mechanism in German and Spanish mainstream parties. Party Politics: DOI: $\underline{10.1177 / 1354068818795195}$

Atkeson L (1998) Divisive Primaries and General Election Outcomes: Another Look at Presidential Campaigns. American Journal of Political Science 42: 256-271.

Brady D, Han H and Pope JC (2007) Primary Elections and Candidate Ideology: Out of step with the Primary Electorate? Legislative Studies Quarterly 32: 79-105.

Bryan M and Jenkins S (2016) Multilevel Modelling of Country Effects: A Cautionary Tale. European Sociological Review 32: 3-22.

Carey JM and Polga-Hecimovich J (2006) Primary Elections and Candidate Strength in Latin America. The Journal of Politics 68: 530-543.

Cross W (1996) Direct Election of Provincial Party Leaders in Canada, 1985-1995: The end of the Leadership Convention? Canadian Journal of Political Science 29: 295315.

Cross W and Pilet JB (eds.) (2015) The Politics of Party Leadership: a cross-national perspective. Oxford: Oxford University Press.

Cross W, Kenig O, Pruysers S, and Rahat G (2016) Promise and Challenge of Party Primary Elections: a comparative perspective. McGill-Queen's University Press.

Hooghe L, Marks G, Schakel A, Osterkatz S, Niedzwiecki S and Shair-Rosenfield S (2016) Measuring Regional Authority: A Postfunctionalist Theory of Governance, Volume I. Oxford: Oxford University Press.

Kaufman K, Gimpel G and Hoffman A (2003) A Promise Fulfilled? Open primaries and Representation. The Journal of Politics 65: 457-476.

Kenig O, Rahat G and Hazan R (2015) Leadership Selection versus Candidate Selection: Similarities and Differences. In Sandri G, Seddone A and Venturino F (eds), Party Primaries in Comparative Perspective. Farnham: Ashgate Publishing Limited, pp. 21-39.

Kenney P and Rice T (1987) The Relationship between Divisive Primaries and General Election Outcomes. American Journal of Political Science, 31: 31-44. 
Key V 1947. Politics, Parties and Pressure Groups. New York: Thomas Y. Crowell Company.

Lehrer R, Ezrow L, Ward H and Bohmelt T (2017) Intra-Party Democracy and Responsiveness to Rival Parties' Policies. Social Science Quarterly 98: 1026-1044.

Lengle J, Owen D and Sonner M (1995) Divisive Nominating Mechanisms and Democratic Party Electoral Prospects. The Journal of Politics 57: 370-383.

Michels R (1949) Political Parties: A Sociological Study of the Oligarchical Tendencies of Modern Democracy. Illinois: The Free Press.

Norrander B (1989) Ideological Representativeness of Presidential Primary Voters. American Journal of Political Science, 33: 570-587

Pedersen H and Schumacher G (2015) Do Leadership Changes Improve Electoral Performance? In Cross W and Pilet JB (eds), The Politics of Party Leadership: A Cross-National Perspective. Oxford: Oxford University Press, pp. 149-164.

Poguntke T and Webb P (2005) The presidentialization of politics: A comparative study of modern democracies. Oxford: Oxford University Press.

Ramiro L (2016) Effects of party primaries on electoral performance: The Spanish Socialist primaries in local elections. Party Politics 22: 125-136.

Sandri G, Antonella S and Venturino F (eds) (2015) Party Primaries in Comparative Perspective. Farnham: Ashagate Publishing Limited.

Samuels D and Shugart M (2010) Presidents, Parties, and Prime Ministers: How separation of powers affects party organization and behavior. Cambridge: Cambridge University Press.

Williams L (2015) It's All Relative: Spatial Positioning of Parties and Ideological Shifts. European Journal of Political Research 54: 141-59.

Young L and Cross W (2002) The Rise of Plebiscitary Democracy in Canadian Political Parties. Party Politics 8: 673-699.

\footnotetext{
${ }^{1}$ In both countries, however, we have also included as 'primary' elected those top candidates who were party leaders previously selected by primaries.

${ }^{2}$ Christlich-Soziale Union (CSU) in Bavaria.

${ }^{3}$ Quebec is excluded because neither the Conservative party nor the NDP ran candidates. The three Canadian territories of Yukon, Northwest Territories and Nunavut are also excluded from the analysis, either because of their non-partisan politics or the lack of data about how party leaders were selected.
} 
${ }^{4}$ The data have been obtained from the respective national institutes of statistics (the Statistics CanadaStatistique in Canada, the Bundesagentur für Arbeit in Germany, and the Instituto Nacional de Estadística in Spain).

${ }^{5}$ The results do not change appreciably if region dummies are used instead of country dummies.

${ }^{6}$ This explains why the number of observations in Table 5 drops from the first to the second model.

${ }^{7}$ The number of observations changes across the models due to the availability of information.

${ }^{8}$ We have not found that primaries held in temporal proximity to elections increase the penalty when there is a single candidate or the primary is not competitive. 